\title{
The relationship between sedentary behaviours and nutrient intakes in young adults
}

\author{
Amelia A. Lake, Tim Townshend, Seraphim Alvanides and Ashley J. Adamson \\ Newcastle University, Newcastle upon Tyne, UK
}

Being overweight in adolescence is associated with numerous factors, including sedentary behaviour ${ }^{(1)}$. As young adults progress through adolescence there is an increase in computer use and a decrease in moderate-to-vigorous physical activity ${ }^{(2)}$. Previous research has associated 'screen behaviour' with increased consumption of sugar-sweetened drinks ${ }^{(3)}$. Little is known about the numerous other forms of sedentary behaviour that young adults engage in, particularly in the transition through to adulthood.

The present pilot study recruited seventy-three 16-20 year olds in full-time education in Newcastle, England. Participants completed a UK version of the Youth Neighbourhood Environment Walkability Survey (NEWS) ${ }^{(4)}$, which included measures of sedentary behaviour and a validated FFQ (modified EPIC ${ }^{(5)}$ ). A rank for index of multiple deprivation (IMD) was assigned to their home post code. Analysis explored associations between sedentary behaviours and nutrient intake.

There were no significant differences in nutrient intake according to sample quartile IMD position. Sedentary behaviours were significantly associated with less-healthy eating patterns. Time spent 'watching television (TV), videos or DVDs and listening to music' during the week was significantly associated with percentage energy from fat $(P=0.006)$; intake was lower in individuals who reported watching TV and DVDs or listening to music throughout the week for 0-30 min compared with those who spent $\geq 3-4 \mathrm{~h}$. For weekend 'TV, video or DVD viewing and listening to music', total energy intake $(P=0.02)$, fat intake $(P=0.005)$, percentage energy from fat $(P=0.035)$, and percentage energy from carbohydrate $(P=0.004)$ was significantly different between the three time groups $(0-30$ min, 1-2 $\mathrm{h}$ and $\geq 3-4 \mathrm{~h}$ ). Those participants who reported greater amounts of screen time or listening to music had higher intakes of fat and percentage energy from fat, lower percentage energy from carbohydrates and higher total energy intakes.

Individuals who reported spending $\geq 3-4 \mathrm{~h}$ on their homework during the week had a significantly higher intake of vitamin $\mathrm{C}$ than those spending $0-30 \mathrm{~min}$ and $1-2 \mathrm{~h}(P=0.016)$. There were significant differences in intake of energy $(P=0.002)$, fat $(P=0.009)$, carbohydrate $(P<0.001)$, total sugars $(P<0.001)$ and vitamin $\mathrm{C}(P=0.044)$ according to reported time spent doing homework at the weekend.

Those participants who reported spending 0-30 min at the weekend 'sitting talking on the telephone, texting or hanging out with family or friends' had a lower percentage contribution to total energy from fat (31) compared with those spending 1-2 (35) or $\geq 3-4 \mathrm{~h}$ (34; $P=0.035)$.

Higher reported time spent 'sitting or driving in a car' during the week was associated with higher fat intake $(P=0.014)$ and lower carbohydrate intake $(P=0.036)$. Greater amounts of reported time spent sitting or driving in a car at the weekend was associated with significantly higher energy intake $(P=0.035)$ and higher fat intake $(P=0.016)$.

Respondents who were more sedentary had a less-healthy diet in terms of higher energy and fat intakes and lower carbohydrate intakes. This combination of sedentary behaviour and less-healthy eating patterns has important implications for long-term health, such as the tracking of overweight and obesity from adolescence into adulthood ${ }^{(6)}$. Longitudinal research has indicated that TV viewing in adolescence can be associated with overweight, poor fitness, smoking and raised cholesterol in adulthood ${ }^{(7)}$. Young adults spend $2-2.5 \mathrm{~h} / \mathrm{d}$ watching TV, $0.5 \mathrm{~h}$ using computers and $0.75 \mathrm{~h}$ using video games ${ }^{(8)}$. These respondents spent at least $1-2 \mathrm{~h}$ on weekdays and $\geq 3-4 \mathrm{~h} / \mathrm{d}$ during the weekend, 'watching TV, videos, DVD and listening to music'. Those respondents who spent more time on this behaviour had a higher contribution from fat to their energy intake. Across a number of countries young adults who watched more TV were more likely to consume sweets and soft drinks and less likely to consume fruit and vegetables ${ }^{(9)}$. Understanding behaviour relationships is an important step in developing interventions in this age-group who are in a period of transition.

Amelia Lake and Ashley Adamson are both funded by NIHR Personal Awards.

1. Patrick K, Norman GJ, Calfas KJ, Sallis JF, Zabinski MF, Rupp J \& Cella J (2004) Arch Pediatr Adolesc Med 158, 385-390.

2. Nelson MC, Neumark-Stzainer D, Hannan PJ, Sirard JR \& Story M (2006) Pediatrics 118, e1627-e1634.

3. Kremers SPJ, van der Horst K \& Brug J (2007) Appetite 48, 345-350.

4. Kerr J, Saelens B, Rosenberg D et al. (2006) Active where?: Multi-region formative research to understand children's physical activity environments. http://www.activelivingresearch.org/alr/files/2006_children_parks_recreation_kerr.pdf

5. Bingham SA, Welch AA, McTaggart A et al. (2001) Public Health Nutr 4, 847-858.

6. Viner RM \& Cole TJ (2006) Int J Obes (Lond) 30, 1368-1374.

7. Hancox RJ, Milne BJ \& Poulton R (2004) Lancet 364, 257-262.

8. Marshall SJ, Gorely T \& Biddle SJ (2006) J Adolesc 29, 333-349.

9. Vereecken CA, Todd J, Roberts C, Mulvihill C \& Maes L (2006) Public Health Nutr 9, 244-250. 